IFAS Extension

\title{
Healthy Living: \\ Scrambling for a Variety of Foods ${ }^{1}$

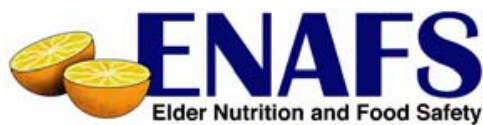

Linda B. Bobroff ${ }^{2}$

Unscramble the following words to spell some of the foods that are best for good health. Then write down each of the numbered letters on the blanks below to figure out the message!

\section{MILK}

G O U Y T R $\frac{-}{4}-\frac{-}{4}-$

E H E C E S $--\frac{-}{1}--$

\section{MEAT AND BEANS}

T I P N O E B N A S

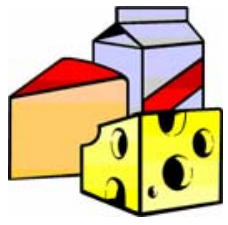

FRUITS

U C J I E

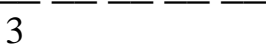

P E H A C

G A R E S P

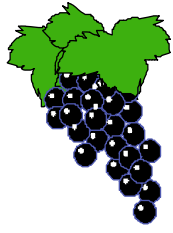

\section{GRAIN FOODS}

N A P K C A E

R A B E D

\section{VEGETABLES}

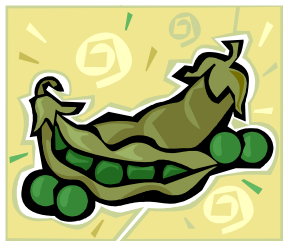

E C Y E L R 9

T O O P A

$----\frac{-}{9}$

MESSAGE:

$$
\overline{1} \overline{2} \overline{3} \overline{4} \overline{5} \quad \overline{6} \overline{7} \overline{8} \overline{9} \quad \overline{10} \overline{11} \overline{12} \overline{13} \overline{14}
$$

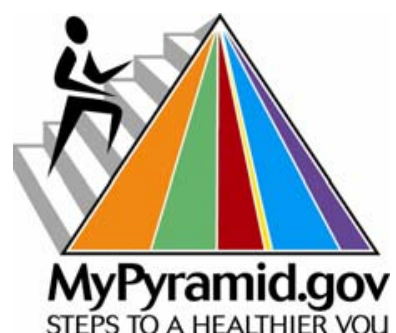

1. La version en español de este folleto es Vida Saludable: Lestras en Desorden (FCS8615span). This leaflet, FCS8615, one in a series of the Department of Family, Youth and Community Sciences, Florida Cooperative Extension Service, Institute of Food and Agricultural Sciences, University of Florida, Gainesville, FL 32611. First published date: March 2004. Revised October 2006. Please visit the EDIS Web site at http://edis.ifas.ufl.edu

2. Linda B. Bobroff, PhD, RD, LD/N, professor, Department of Family, Youth and Community Sciences, Institute of Food and Agricultural Sciences, Cooperative Extension Service, University of Florida, Gainesville, FL 32611. Leaflet design by Paulina Wittkowsky, MS, RD, formerly with the University of Florida. 